\title{
CONTINUING PROFESSIONAL EDUCATION
}

\section{A glossary on psychiatric epidemiology}

\author{
Huibert Burger, Jan Neeleman
}

J Epidemiol Community Health 2007;61:185-189. doi: 10.1136/jech.2003.019430

$\mathrm{P}$ sychiatric epidemiology constitutes an important subdiscipline of scientific psychiatry. Nevertheless, it still lags behind other branches of epidemiology. This has been attributed to the difficulties encountered in conceptualising and measuring mental disorders. ${ }^{1}$ It is only recently that the emphasis in the field has shifted from descriptive to analytical research and this is probably because of the influences from genetic epidemiology and social sciences. ${ }^{2}$ Psychiatric epidemiology has taken most of its tools from general epidemiologythat is, chronic disease epidemiology. ${ }^{3}$ It is therefore not surprising that no fundamental differences between the mother discipline and her psychiatric descendant exist. Yet, there are particular challenges in the conduct of psychiatric epidemiological research that are absent or less prominent in general, mostly somatically oriented, epidemiology. Challenges particularly encountered in psychiatric epidemiology include

1. Assessment of caseness: psychiatric diagnoses are mostly made on the basis of symptomspatients' reports of their subjective experiences-and not signs, like fever in general medicine. Moreover, there are no pathognomonic symptoms or signs;

2. Neither most mental disorders nor their bestknown risk factors, like social deprivation, stress exposure, lack of social support, social isolation, abnormal personality traits or genetic liability, are as easily captured in a singular variable as tends to be the case in the epidemiology of somatic disease;

3. Making a psychiatric diagnosis is costly in time and effort; and

4. Information bias and non-response bias are more of a problem in psychiatric epidemiology than in other branches of epidemiology.

In our view, this warrants recognition of the epidemiology subspecialty "psychiatric epidemiology".

In trying to cope with the above-mentioned

See end of article for authors' affiliations

......................

Correspondence to: Dr H Burger, Senior Lecturer in Psychiatric Epidemiology, Julius Center for Health Sciences and Primary Care, University Medical Center Utrecht, PO Box 85500 3508 GA, Utrecht, The Netherlands; h.burger@ umcutrecht.nl

Accepted 18 April 2005 challenges, psychiatric epidemiology has developed a set of concepts, albeit limited, and vocabulary of its own. The purpose of this glossary is to provide brief definitions, sometimes with comments, of frequently used special terms one may come across in dealing with psychiatric epidemiology. Although we consider general epidemiologists the primary audience of this glossary, it may be of interest to all health professionals involved in psychiatry. The terms in this glossary were either thought up by the authors themselves or suggested by experts who were consulted using an email conference.

\section{CAPTURE-RECAPTURE}

This is a technique adopted from biology for estimating the size of a population that cannot be enumerated directly because only a fraction is observable - that is, a "hidden" population. First, a random sample from the population of interestfor example, 300 patients with a certain disorderis drawn. Next, these patients are registered and after some time, in which these patients are assumed to be completely mixed with the total, "hidden" population, a second random sample is drawn. From the prevalence of the registered patients in the second sample, for instance 0.2, the size of the total population may be calculated, in the above example $1 / 0.2 \times 300=1500$ patients. The validity of this technique depends on the representativeness of the samples, the independency of the samples and their homogeneity. Independency and homogeneity may be tested and, if necessary, adjusted for. ${ }^{5}$

\section{CASE}

The definition of "caseness" (ie, whether or not a subject has the condition of interest) is essential in all epidemiology, but especially so in psychiatric epidemiology where often, other than clinical impression, no objectively assessable measures exist to establish the presence or absence of a given syndrome. ${ }^{6}$ The uncertainty is related to the possibility that mental illness is expressed along a continuum, ${ }^{7}$ the absence of identified endophenotypes for mental disorders and the ongoing debates about the validity of diagnostic categories that, as in the Diagnostic and Statistical Manual, essentially have been derived from consensus among clinicians

\section{CASE REGISTRY}

This is essentially a database with data on demography and limited clinical data such as diagnosis of people who were in contact with a mental healthcare organisation in a certain geographical area. The data are particularly useful for research purposes if linked to other registries-for example, birth registries or medical registries. ${ }^{8}$

\section{CENTER FOR EPIDEMIOLOGICAL STUDIES OF DEPRESSION (CES-D) SCALE'}

This scale is considered a self-report standard measure of depressive symptomatology in elderly people and has shown good psychometric properties in general. When used in elderly people with considerable somatic morbidity, however, item bias may threaten its validity. ${ }^{10}$

Abbreviations: $\mathrm{CIDI}$, composite international diagnostic interview; DSM, diagnostic and statistical manual 


\section{COMORBIDITY}

Comorbidity is a term coined by Feinstein denoting the joint occurrence of more somatic or psychiatric disorders with different pathophysiology in a single person, either simultaneously or on a lifetime basis. ${ }^{11}$ Various types have been distinguished: episode versus lifetime comorbidity, coincidental comorbidity (co-occurrence by chance), and cluster, dependent or associative comorbidity. In the last three types that are synonyms, disorders either act as risk factors for each other or share underlying risk factors. ${ }^{12}$ Comorbidity is a major research issue in psychiatric epidemiology raising substantial conceptual and methodological discussion. ${ }^{313}$

\section{COMPOSITE INTERNATIONAL DIAGNOSTIC INTERVIEW}

This is an amalgamation of questions from the Diagnostic Interview Schedule and the Present State Examination. ${ }^{14}$ It was designed for use by lay interviewers and allows computerised diagnostic assessments. The composite international diagnostic interview (CIDI) comprises 11 diagnostic modules and generates both Diagnostic and Statistical Manual (DSM) diagnoses and International Classification of Disease diagnoses, as well as symptom profiles.

\section{CONTINUUM}

This is a variable that has no steps between two points. Psychiatric disorders may be measured along a continuum if a fluent transition from normal to pathological psychological states can be presumed, as seems the case for many if not all somatic diseases (eg, cardiovascular disease). Several instruments such as the Symptom Checklist and the General Health Questionnaire are available to measure dimensions like depression, anxiety and paranoid ideation along a continuum. ${ }^{15}{ }^{16}$

\section{DENSITY}

This term refers to the prevalence of the risk factors in the study population and was probably coined by Rabkin in psychiatric epidemiology. ${ }^{17}$ It fits into the multilevel or contextual approach to epidemiological analysis in which not only the distribution of the risk factor (distributional effects) but also its prevalence (compositional effects) interact to set the observed risk of the outcome. This term should not be confused with "incidence density", which indicates the occurrence of new disease per person-year of observation.

\section{DIAGNOSTIC INTERVIEW SCHEDULE}

This is a standardised interview developed principally for use in the Epidemiological Catchment Area Studies. ${ }^{18}$ Unlike the Schedule for Clinical Assessment in Neuropsychiatry and the Research Diagnostic Criteria interviews, it can be administered by lay interviewers, provided they have received training. ${ }^{18}$ Its present day successor is the CIDI, which was used in the National Comorbidity Survey.

\section{DIAGNOSTIC AND STATISTICAL MANUAL}

The preoccupation with the question of "caseness" has led to the development of diagnostic criteria to improve the reliability of psychiatric diagnoses. The first edition of the Diagnostic and Statistical Manual was published in 1952, and based on the US military's diagnostic criteria. The second edition was published in 1968, followed by the third edition in 1980 and a revision in 1987. The DSM-IV appeared in 1994 and contains a recent definition of mental disorders.

\section{EPIDEMIOLOGICAL CATCHMENT AREA STUDY}

This investigation of the prevalence of psychiatric comorbidity was undertaken during 1976-80 in five sites in the USA. ${ }^{19}$ More than 20000 people were interviewed using the Diagnostic Interview Schedule. A main criticism was its use of lifetime diagnoses, which may be unreliable due to recollection bias.

\section{ETIC/EMIC APPROACHES}

The so-called etic (or universalist) approach to psychiatric diagnosis rests on the quite strong assumption that caseness of mental illness is similar in any social, cultural or national context. DSM criteria and dichotomies broadly rest on this assumption. The "emic" or cross-cultural approach aims to take cultural differences between mental disorders into account. ${ }^{20}$

\section{GENERAL HEALTH QUESTIONNAIRE}

This is the most widely used self-report questionnaire to assess the likelihood that significant mental illness is present. ${ }^{16}$

\section{GENERATION}

To describe the development of psychiatric epidemiology, three "generations" of studies are distinguished. Before World War 2, there were an estimated 16 psychiatric-epidemiological studies of the so-called lst generation. ${ }^{2}$ These studies focused primarily on the administrative (ie, registered by healthcare and other agencies) prevalence of mental disorders in relation to community characteristics such as the number of "broken homes, few and weak community associations, inadequate leadership, few recreational activities, hostility and inadequate communication, as well as poverty, secularisation and cultural confusion", ${ }^{21}$ a state called "anomie" by the sociologist Émile Durkheim who pioneered the sociological study of suicide..$^{22}$ The 2nd generation of psychiatric epidemiological studies was sparked off by an increased interest in the nomenclature of psychiatric disorders after World War 2; approximately 60 2nd generation studies appeared, mainly field surveys conducted by psychiatrists and psychologists in unstructured clinical face-toface interviews. However, the reliability of these was low. The 3rd generation studies were set off around 1970 and differed from 2nd generation studies in that more effort was put into increasing the reliability of psychiatric diagnoses. A landmark in achieving this was the publication of the Diagnostic and Statistical Manual, 3rd edition, in 1980, ${ }^{23}$ a set of operational diagnostic criteria for 357 psychiatric syndromes. A major preoccupation of 3rd generation studies has been, and remains, to obtain precise estimates of prevalence (and sometimes incidence) of specific mental disorders, whereas 2nd generation studies focused on mental ill-health in general.

\section{ITEM BIAS}

People with the same level of the underlying dimension should respond to an item in the same way, regardless of any other characteristic. If this is not the case, item bias may occur. The inclusion of many somatic depressive symptoms in the CES-D scale, for instance, may generate spuriously high depression scores in the elderly, as they generally have more physical problems. Grayson et al found and their findings indeed indicated that substantial physical disorder-related artefacts with the CES-D scale total score exist. ${ }^{10}$

\section{KING LEAR PRINCIPLE}

This is the idea that mild psychopathology is obscured by the more severe psychopathology, which implies a natural hierarchy of psychiatric disease. It was named after a citation from Shakespeare's King Lear: "Where the greater malady is fixed, the lesser is scarce felt". ${ }^{24}$ 


\section{LIFE EVENT}

This is a psychologically distressing occurrence such as the loss of a family member, receiving a diagnosis of severe disease or serious financial problems. There are several methodological problems with the assessment of life events and there has been wide discussion on whether life events can be reliably assessed using self-rating questionnaires, or whether in-depth contextual interviews are necessary. ${ }^{25}$ An important development in the formal assessment of life events has been the widely used Life Events and Difficulties Schedule, a semistructured interview originating from social psychiatry. ${ }^{26}$ Life events have convincingly been shown to be associated with an increased risk of major depression among those with an increased genetic susceptibility to this disorder. ${ }^{27}$ A similar pattern seems to exist for schizophrenia-that is, certain genes are associated with an increased risk for schizophrenia by making individuals more sensitive to environmental risk factors such as life events, or by making individuals more likely to select high-risk environments. $^{28}$

\section{MENTAL DISORDERS}

According to the DSM IV, a mental disorder can be defined as follows: "a clinically significant behavioral or psychological syndrome or pattern that occurs in a person and that is associated with present distress (a painful symptom) or disability (ie, impairment in one or more important areas of functioning) or with a significantly increased risk of suffering death, pain, disability or an important loss of freedom. In addition, this syndrome or pattern must not be merely an expectable and culturally sanctioned response to a particular event, for example, the death of a loved one. Whatever its original cause, it must currently be considered a manifestation of a behavioral, psychological or biological dysfunction in the individual. Neither deviant behavior (eg, political, religious or sexual) nor conflicts that are primarily between the individual and society are mental disorders unless the deviance or conflict is a symptom of a dysfunction in the individual, as described above." ${ }^{\prime 29}$

\section{MULTI-INFORMANT ASSESSMENT}

This is the assessment of psychopathology based on different informants. This procedure is frequently, but not exclusively, used in child and adolescent psychiatry where commonly teachers, parents and the children or adolescents themselves provide information on the presence of psychopathology, all from a different perspective. The reports from different informants often show discrepancies in classifying subjects as disordered or normal. As it is felt that no informant is intrinsically superior, the results are frequently presented for the different informants separately. ${ }^{30}$

\section{MULTILEVEL DESIGN}

The context in which an individual is exposed to a certain risk factor may be a determinant of the magnitude of its effect. This so called ecological or contextual effect modification can be studied using multilevel designs in which data on both individual exposures and contextual variables are analysed simultaneously. ${ }^{31}$

\section{NATIONAL COMORBIDITY SURVEY}

This was a survey carried out among a nationally representative sample ( $\mathrm{n}=8098 ; 15-54$ yrs) of US citizens. ${ }^{32}$ The CIDI was used as an instrument for use by lay interviewers. ${ }^{14}$ This study showed the widespreadness of mental illness: one of its results was that approximately $30 \%$ had experienced a psychiatric disorder in the previous year.

\section{NATURE OF NURTURE}

Also denoted as gene-environment correlation, this is the phenomenon that genetic factors cause a person to create specific experiences and environments-for example, genetic influences on perceived parental warmth by a child. ${ }^{33}$

\section{NEEDS FOR CARE}

The needs for care for mental disorders form an underresearched area as compared with the prevalence of mental disorders. In the well-known Camberwell Needs for Care Survey, it was found that nearly $10 \%$ of the population had a need for treatment of a psychiatric condition, that less than half of all potentially meetable needs were met, and that most needs could be managed by family doctors. ${ }^{34}$ In a recent study by the World Health Organization, it was shown that in the lessdeveloped countries approximately $80 \%$ of cases of serious mental disorders received no treatment, as compared with around $40 \%$ in the more-developed countries. ${ }^{35}$

\section{PATHWAYS TO CARE}

This model, developed by Goldberg and Huxley, gives an account of how mental illness interacts with the healthcare system. ${ }^{36}$ Originally, five levels of mental illness occurrence were described: that at the community (260-315/1000/year), that at all primary care attenders (230/1000/year), that at primary care attenders in whom the mental illness has been recognised (conspicuous morbidity; 101.5/1000/year), that at the level of psychiatrist (23.5/1000/year), and that at the level of psychiatric inpatient care (5.7/1000/year). Three, sometimes four filters, that explain the decreasing incidence when going from the general population to inpatient psychiatric care are known: at the level of the patient himself or herself (recognition), at the level of the general practitioner (recognition, decision to treat, decision to refer on), at the outpatient level of the mental healthcare system and, finally, at the inpatient level. Accordingly, this model is also denoted a "filter model".

\section{PERSONALITY}

Personality traits are considered enduring patterns of perceiving, relating to and thinking about the environment and oneself, exhibited in a wide range of important social and personal contexts. ${ }^{37}$ The five-factor model or "big five" comprises five continuous personality dimensions or traits: openness to experience, conscientiousness, extraversion, agreeableness and neuroticism. ${ }^{38}$ At present, it is the dominant model for studying personality traits. The factors were derived from factor analyses of a large number of self and peer reports. Today, they may be easily assessed using the selfadministered paper-and-pencil form of the Revised Neo Personality Inventory. ${ }^{39}$ At present, alternatives to the fivefactor model with particular relevance to clinical practice (eg, the Shedler-Westen Assessment Procedure) are being developed. ${ }^{40}$

\section{PERSONALITY DISORDER}

Personality disorder is an enduring pattern of inner experience and behaviour that deviates markedly from the expectations of the individual's culture, is pervasive and inflexible, has an onset in adolescence or in early adulthood, is stable over time, and leads to distress to self or others, or impairment of behaviour and/or social functioning. Although the onset is usually in adolescence or early adulthood, personality disorders can arise later on in life as well. Not uncommonly, they may result from organic brain syndromes-for example, after a road traffic injury. ${ }^{29}$ Personality disorders have been assigned a separate axis (axis II) in the diagnostic nomenclature and, compared 
with many axis I disorders such as schizophrenia or depression, they have been less subject to empirical research. The current DSM approach to diagnosing personality disorders is a typological one, whereas dimensional approaches have also been used, particularly in research settings. ${ }^{41}$

\section{PHARMACOGENETICS}

The response of patients to psychotropic drugs as well as the likelihood of adverse effects is not invariant. As a result, certain patients are exposed to ineffective treatment or an increased risk of adverse effects during some time. The evolving field of pharmacogenetics seeks genetic approaches to solve this problem. Ultimately, this field aims to provide genetic knowledge for stratifying patients according to the probability of therapeutic response or side effects before treatment is initiated. Genetic variants relating to the efficacy and adverse effects of antipsychotics and antidepressants have so far been identified..$^{42}$

\section{PRESENT STATE EXAMINATION}

This is the original version of the Schedule for Clinical Assessment in Neuropsychiatry. ${ }^{43}$ It constitutes the first structured psychiatric interview and it allowed generation of the International Classification of Diseases and, later, DSMdiagnoses by means of a computer program (CATEGO).

\section{PREVENTION}

True prevention, most often called primary prevention, implies reduction or eradication of well-known risk factors for a disease at the population level. For most psychiatric disorders, this seems an unrealistic option. Many risk factors are not easily modified; genetic predisposition in the first place and also personality factors, intrauterine hazards to the developing brain, socioeconomic status and many adverse life experiences are not at all or only to a limited extent open to intervention. Possibilities for secondary prevention-that is, early detection and management of those with risk factors or subclinical prodromes of disease-are currently being researched for the psychoses. Strategies are being developed that aim at preventing or postponing a first florid psychosis by early detection and intervention-for example, cognitive-behavioural therapy or even pharmacotherapy in the prodromal phase of psychosis. ${ }^{44}$ Secondary prevention of depression seems effective in some groups of patients, for instance those who have experienced a stroke. ${ }^{45}$ Tertiary prevention involves treatment of established disease to prevent disease-related complications-for example, prevention of suicide in patients with schizophrenia. ${ }^{46}$

\section{RELIABILITY}

Reliability is the degree to which a measurement produces consistent results, most importantly test-retest and interobserver consistency. Contrary to low validity of a psychiatric assessment instrument, low reliability can often easily be fixed by structuring and standardising the assessment procedure. ${ }^{47}$ Despite many efforts in this area, there still tends to be considerable discrepancy between diagnoses obtained by different fully structured interviews. ${ }^{48}$

\section{SCHEDULE FOR CLINICAL ASSESSMENT IN NEUROPSYCHIATRY}

This is essentially the 10th revision of the Present State Examination. ${ }^{49}$ It has shown excellent reliability, validity and practical applicability. Its modular structure allows limiting the interview to those questions that are needed for subsets of psychiatric problems.

\section{SOCIAL CAPITAL}

Social capital refers to the institutions, relationships and norms that shape the quality and quantity of a society's social interactions. Increasing evidence shows that social cohesion is critical for societies to prosper economically and for development to be sustainable. Social capital is not just the sum of the institutions that underpin a society-it is the glue that holds them together. ${ }^{50}$

\section{SYNERGY}

According to the Last Dictionary of epidemiology, one of the (controversial) definitions of synergy reads: "a situation in which the combined effect of two or more factors is greater than the sum of their solitary effects" ${ }^{\prime 51}$ If an effect is measured as a risk difference or relative risk, which is often the case in epidemiology, synergy is statistically assessed as additive or multiplicative interaction, respectively. The assessment of synergy finds an important application in the study of geneenvironment interaction. For instance, van Os and coworkers found that approximately $60-70 \%$ of the individuals exposed to both urbanicity and familial liability had developed psychotic disorders because of the synergistic action of the two proxy causes. $^{52}$

\section{SYMPTOM CHECKLIST-90-REVISED}

This is a 90-item questionnaire designed for the purpose of screening for current psychopathology. It assesses nine symptom constructs on a continuous scale: somatisation, obsessivecompulsive symptoms, interpersonal sensitivity, depression, anxiety, hostility, phobia, paranoid ideation and psychoticism..$^{53}$

\section{VALIDITY}

This is the extent to which an empirical indicator of a concept actually represents the concept of interest. There are three types of validity that need consideration when a measurement instrument is evaluated. (1) Content validity refers to the extent of representation of essential features of a phenomenon under study in an instrument. ${ }^{54}$ For example, if an instrument has to measure depression, content validity requires inclusion of items referring to gloomy feelings, sleeping disturbances, etc. There are no statistical means of assessing content validity. (2) Criterion validity is concerned with measuring something external to the measurement of the concept itself. ${ }^{55}$ External to the measurement itself may be the sequelae of the concept. This form of criterion validity is therefore called "predictive validity". Another form of criterion validity is "concurrent validity". It refers to the extent to which a measure correlates with an external criterion at the same point in time-for example, a certain brain abnormality in the assessment of schizophrenia. Content and criterion validity are necessary but not sufficient conditions for establishing (3) construct validity. This form of validity is related to the extent to which a certain measure of interest fits into what is already known about the concept measured, and its relationship to other measurable phenomena. ${ }^{54}$ It is thus defined in a fully theoretical context.

\section{Authors' affiliations \\ Huibert Burger, Jan Neeleman, Julius Center for Health Sciences and Primary Care, University Medical Center Utrecht, Utrecht, The Netherlands \\ Funding: $\mathrm{HB}$ is, in part, supported by the Dutch Organization for Scientific Research (ZonMw Fellowship no 2610-0002). JN is, in part, supported by the Dutch Organization for Scientific Research (ZonMW Pioniergrant no} 900-00-002)

Competing interests: None. 


\section{REFERENCES}

1 Kessler RC. Psychiatric epidemiology: selected recent advances and future directions. Bull World Health Organ 2000;78:464-74.

2 Dohrenwend BP. A psychosocial perspective on the past and future of psychiatric epidemiology. Am J Epidemiol 1998;147:222-31.

3 Batstra L, Bos EH, Neeleman J. Quantifying psychiatric comorbidity-lessons from chronic disease epidemiology. Soc Psychiatry Psychiatr Epidemiol 2002;37:105-11

4 Fleming JA, Hsieh CC. Introduction to epidemiologic research methods. In: Tsuang MT, Tohen M, eds. Textbook in psychiatric epidemiology. New York: Wiley-Liss, 2002.

5 Hook EB, Regal RR. Internal validity analysis: a method for adjusting capturerecapture estimates of prevalence. Am J Epidemiol 1995; 142:S48-S52.

6 Williams P, Tarnopolsky A, Hand D. Case definition and case identification in psychiatric epidemiology: review and assessment. Psychol Med 1980;10:101-14

7 Goldberg DP, Oldehinkel T, Ormel J. Why GHQ threshold varies from place to place. Psychol Med 1998;28:915-21.

8 Mors O, Mortensen PB, Ewald H. A population-based register study of the association between schizophrenia and rheumatoid arthritis. Schizophr Res 1999;40:67-74

9 Radloff LS. The CES-D scale: a self-report depression scale for research in the general population. Appl Psychol Measurement 1977;1:385-401.

10 Grayson DA, Mackinnon A, Jorm AF, et al. Item bias in the center for epidemiologic studies depression scale: effects of physical disorders and disability in an elderly community sample. J Gerontol B Psychol Sci Soc Sci 2000:55:273-82.

11 Feinstein AR. The pretherapeutic classification of comorbidity in chronic disease. J Chronic Dis 1970;23:455-68.

12 Anderson J, Huppert F, Rose G. Normality, deviance and minor psychiatric morbidity in the community. A population based approach to $\mathrm{GHQ}$ data in the Health and Lifestyle Survey. Psychol Med 1993;23:475-85.

13 Vella G, Aragona M, Alliani D. The complexity of psychiatric comorbidity: a conceptual and methodological discussion. Psychopathology 2000;33:25-30.

14 Robins LN, Wing J, Wittchen HU, et al. The Composite International Diagnostic Interview. An epidemiologic Instrument suitable for use in conjunction with different diagnostic systems and in different cultures. Arch Gen Psychiatry 1988;45:1069-77.

15 Derogatis LR. SCL-90; an outpatient psychiatric rating scale. Psychopharmacol Bull 1973;9:13-28.

16 Goldberg D. The detection of psychiatric illness by questionnaire. London: Oxford University Press, 1972.

17 Rabkin JG. Ethnic density and psychiatric hospitalization: hazards of minority status. Am J Psychiatry 1979;136:1562-6.

18 Robins LN, Helzer JE, Croughan J, et al. National Institute of Mental Health Diagnostic Interview Schedule. Its history, characteristics, and validity. Arch Gen Psychiatry 1981;38:381-9.

19 Regier DA, Myers JK, Kramer M, et al. The NIMH Epidemiologic Catchment Area program. Historical context, major objectives, and study population characteristics. Arch Gen Psychiatry 1984;41:934-41.

20 Kleinman A. Anthropology and psychiatry. The role of culture in cross-cultural research on illness. Br J Psychiatry 1987; 151:447-54.

21 Leighton DC, Harding JS, Macklin DB, et al. The characteristics of danger. New York: Basic Books, 1963.

22 Durkheim E. Suicide: a study in sociology [translated by J A Spaulding \& G Simpson]. Illinois: Free Press, 1951.

23 American Psychiatric Association. Diagnostic and Statistical Manual of Mental Disorders: DSM-III. Washington: APA, 1980.

24 Foulds GA. The hierarchical nature of personal illness. London: Academic Press, 1976.

25 Brown GW, Harris T. Social origins of depression: a study of psychiatric disorder in women. London: Tavistock, 1978.

26 Brown G, Harris T. Life events and measurement. Life events and illness. New York: Guilford Press, 1989.
27 Kendler KS, Kessler RC, Walters EE, et al. Stressful life events, genetic liability, and onset of an episode of major depression in women. Am J Psychiatry $1995 ; 152: 833-42$

28 van Os J, Marcelis M. The ecogenetics of schizophrenia: a review. Schizophr Res 1998;32:127-35

29 American Psychiatric Association. Diagnostic and statistical manual of mental disorders: DSM-IV. Washington DC: APA, 1994.

30 Verhulst FC, van der Ende J, Ferdinand RF, et al. The prevalence of DSM-III-R diagnoses in a national sample of Dutch adolescents. Arch Gen Psychiatry 1997;54:329-36.

31 Neeleman J, Halpern D, Leon D, et al. Tolerance of suicide, religion and suicide rates; an ecological and individual-level study in 19 western countries. Psychol Med 1997;27:1165-71

32 Kessler RC, McGonagle KA, Zhao S, et al. Lifetime and 12-month prevalence of DSM-III-R psychiatric disorders in the United States. Results from the National Comorbidity Survey. Arch Gen Psychiatry 1994;51:8-19.

33 Plomin R. The nature of nurture. Genetics and experience. The interplay between nature and nurture. London: Sage, 1994:41-79.

34 Bebbington PE, Marsden L, Brewin CR. The need for psychiatric treatment in the general population: the Camberwell Needs for Care Survey. Psychol Med 1997;27:821-34.

35 Demyttenaere K, Bruffaerts R, Posada-Villa J, et al. Prevalence, severity, and unmet need for treatment of mental disorders in the World Health Organization World Mental Health Surveys. JAMA 2004;291:2581-90.

36 Goldberg D, Huxley P. Mental illness in the community: the pathway to psychiatric care. London: Tavistock, 1980

37 American Psychiatric Association. Diagnostic and Statistical Manual of Mental Disorders: DSM-IIIR. Washington: APA, 1987.

38 Digman JM. Personality structure-emergence of the 5-factor model. Annu Rev Psychol 1990;41:417-40.

39 Costa PT, McCrae RR. Revised Neo Personality Inventroy (Neo PI-R) and NEO Five factor Inventory (Noe-FFI). Professional Manual. Odessa, FL: Psychological Assessment Resources, 1992.

40 Shedler J, Westen D. Dimensions of personality pathology: an alternative to the five-factor model. Am J Psychiatry 2004;161:1743-54.

41 McCrae RR, Costa PT Jr. Personality trait structure as a human universal. Am Psychol 1997;52:509-16.

42 Malhotra AK, Murphy GM Jr, Kennedy JL. Pharmacogenetics of psychotropic drug response. Am J Psychiatry 2004;161:780-96.

43 Wing JK, Cooper JE, Sartorius N. The measurement and classification of psychiatric symptoms. Cambridge: Cambridge University Press, 1974.

44 Hafner H, Maurer K, Ruhrmann S, et al. Early detection and secondary prevention of psychosis: facts and visions. Eur Arch Psychiatry Clin Neurosci 2004;254:117-28.

45 Anderson CS, Hackett ML, House AO. Interventions for preventing depression after stroke. Cochrane Database Syst Rev, 2004;CD003689.

46 Pompili M, Girardi P, Ruberto A, et al. Toward a new prevention of suicide in schizophrenia. World J Biol Psychiatry 2004;5:201-10.

47 Shrout PE. Measurement reliability and agreement in psychiatry. Stat Methods Med Res 1998;7:301-17.

48 Brugha TS, Jenkins R, Taub N, et al. A general population comparison of the Composite International Diagnostic Interview (CIDI) and the Schedules for Clinical Assessment in Neuropsychiatry (SCAN). Psychol Med 2001;31:1001-13.

49 Wing JK, Babor T, Brugha T, et al. SCAN. Schedules for Clinical Assessment in Neuropsychiatry. Arch Gen Psychiatry 1990;47:589-93.

50 Henderson S, Whiteford $\mathrm{H}$. Social capital and mental health. Lancet 2003;362:505-6.

51 Last JM. A dictionary of epidemiology. New York: Oxford University Press, 1995.

52 van Os J, Hanssen $M$, Bak M, et al. Do urbanicity and familial liability coparticipate in causing psychosis? Am J Psychiatry 2003:160:477-82.

53 Rush Jr AJ, Pincus HA, First MB, et al. Handbook of psychiatric measures. Washington, DC: American Psychiatric Association, 2000.

54 Nunnally JC. Psychometric theory. New York: McGraw Hill, 1978.

55 Crohnbach L, Meehl PE. Construct validity in psychological tests. Psychol Bull 1955:52:281-302. 